\title{
Validation of energy requirement equations for estimation of breast milk consumption in infants
}

\author{
Stefanie Schoen*, Wolfgang Sichert-Hellert and Mathilde Kersting \\ Research Institute of Child Nutrition (Rheinische Friedrich-Wilhelms-University Bonn), Heinstueck 11 , \\ D-44225 Dortmund, Germany
}

Submitted 20 March 2008: Accepted 25 February 2009: First published online 16 April 2009

\begin{abstract}
Objective: To test equations for calculating infants' energy requirements as a simple and reliable instrument for estimating the amount of breast milk consumed in epidemiological studies where test-weighing is not possible.

Design: Infants' energy requirements were calculated using three different equations based on reference data and compared with actual energy intakes assessed using the $3 \mathrm{~d}$ weighed dietary records of breast-fed infants from the DOrtmund Nutritional and Anthropometric Longitudinally Designed (DONALD) Study.

Setting: A sub-sample of 323 infants from the German DONALD Study who were predominantly breast-fed for at least the first four months of life, and who had $3 \mathrm{~d}$ weighed dietary records and repeated body weight measurements within the first year of life.

Subjects: Healthy, term infants breast-fed for at least 4 months, 0-12 months of age. Results: The overall differences between measured energy intake and calculated energy requirements were quite small, never more than $10 \%$ of total energy intake, and smaller than the mean variance of energy intake between the three days of recording. The equation of best fit incorporated body weight and recent growth, while the worst fit was found for the equation not considering body weight. Conclusions: Breast milk consumption in fully and partially breast-fed infants can be reasonably quantified by calculating the infants' individual energy requirements via simple equations. This provides a feasible approach for estimating infant energy intake in epidemiological studies where test-weighing of breast milk is not possible.
\end{abstract}

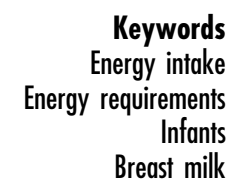

Data on the amount of breast milk consumed by exclusively as well as partially breast-fed infants are mandatory for various epidemiological purposes. For instance, such data are required for evaluating the intake of total energy and specific nutrients in infants ${ }^{(1,2)}$, for investigating the association between breast milk intake and growth $^{(3,4)}$ and for examining potential factors which influence breast milk consumption ${ }^{(5,6)}$. Various methods exist to estimate breast milk consumption including measurement of dose-to-the-mother ${ }^{2} \mathrm{H}_{2} \mathrm{O}$ turnover ${ }^{(1)}$, the test-weighing method $^{(3,4)}$ (where the infant is weighed before and after each breast milk feeding for $24 \mathrm{~h}$ ), assumption of a specific breast milk volume depending on the feeding duration and age of the baby ${ }^{(5,7)}$, and the assumption of a single volume of breast milk (e.g. $750 \mathrm{ml} / \mathrm{d}$ ) irrespective of the age of the breast-fed infant ${ }^{(2,8)}$.

Each of these methods has specific advantages and disadvantages ${ }^{(9)}$. For example, dose-to-the-mother ${ }^{2} \mathrm{H}_{2} \mathrm{O}$ turnover and test-weighing are reportedly the most accurate methods $^{(9)}$ but are not feasible in large epidemiological studies due to the high costs, requirement for personnel and logistics involved. On the other hand, less complex and cheaper methods, such as assuming a single volume of breast milk, do not take into account age, sex, weight, growth or the amount of complementary food consumed in addition to breast milk. Thus, there is a need for a simple and reliable method to estimate breast milk consumption.

It has been shown that, in infants, energy intake (EI) is self-regulated by individual energy requirements $(\mathrm{ER})^{(6,10)}$. This leads to the assumptions that: (i) exclusively breastfed infants consume as much energy via breast milk as determined by their ER; and (ii) partially breast-fed infants consume as much energy via breast milk as determined by the difference between their ER and the EI from foods other than breast milk, e.g. complementary food or formula. Taking self-regulation of EI for granted, data on the measured intake of breast milk, as well as on the intake of all food other than breast milk, are required for healthy, normally growing infants. It would then be possible to calculate their total EI for comparison with their ER. Fortunately, well-documented reference data on the ER (RER) of breast-fed infants are available ${ }^{(11,12)}$ and provide three basic equations for adapting these data to other populations. 
Data on dietary intake including breast milk are available from $3 \mathrm{~d}$ weighed dietary records collected as part of the DOrtmund Nutritional and Anthropometric Longitudinally Designed (DONALD) Study ${ }^{(13,14)}$. Thus, the aim of the present study was to compare the measured EI of breast-fed infants from the DONALD Study with the RER, and to identify which of the three equations best predicts the individual ER. The ultimate objective was to find a simple and reliable instrument for estimating the amount of breast milk consumed in epidemiological studies where test-weighing is not possible.

\section{Methods}

\section{Study population}

The DONALD Study is an ongoing (open) cohort study that collects detailed data on diet, metabolism, growth and development from healthy subjects, from the age of 3 months until 18 years. Data are collected quarterly for each subject (3, 6, 9 and 12 months) in the first year of life, twice in the second year and annually thereafter.

The study started in 1985 with participants of all age groups. Since 1989 approximately forty new infants enter the study each year. Although the DONALD Study sample is biased in having a relatively high socio-economic status, the BMI distribution of the study sample deviates only slightly from the German references ${ }^{(14,15)}$. Likewise, the breast-feeding rates and complementary feeding practices are similar to a nationwide breast-feeding survey ${ }^{(16)}$. Additional details about the DONALD Study have been published elsewhere ${ }^{(13,14)}$.

For the present analysis we selected a sub-sample of term (gestational age $>37$ weeks), healthy infants who were 'predominantly' breast-fed as defined by the $\mathrm{WHO}^{(17)}$ (breast milk only, but water, carbohydrate solutions, fruit juices and medicines are allowed) during the first four months (16 weeks) of life, i.e. the same inclusion criteria as those of the sample used for the $\operatorname{RER}^{(12)}$ calculation.

\section{Dietary assessment}

Dietary intake in the DONALD Study was assessed by $3 \mathrm{~d}$ weighed dietary records collected on three consecutive days. To measure breast milk intake the mothers were supplied with a baby scale ( $\pm 10 \mathrm{~g}$, Soehnle Multina 8300 ) and instructed by trained dietitians to weigh the child before and after each breast-feed (test-weighing). To correct for the systematic error in test-weighing due to insensible water loss, $5 \%$ was added to the test-weighing results $^{(18)}$. Parents were also asked to weigh all solid foods and fluid feeds, such as formula, tea and juices, as well as leftovers, using an electronic food scale $( \pm 1 \mathrm{~g}$, WEDO Digi 2000; Werner Dorsch GmbH, Muenster/ Dieburg, Germany, since 2002 also Soehnle Digita 8000; Leifheit SG, Nassau, Germany). Information on recipes for the preparation of formula (milk powder and water separately) and complementary food (e.g. cereals and fruits separately) was requested. For commercial products labelling details on wrappers, cartons or banderols were also requested. Similarly, details were also collected from labels for medicines and supplements consumed. These were evaluated with the dietary records. Semi-quantitative recording, e.g. numbers of cups and spoons, was allowed if weighing was not possible.

EI from dietary records was calculated using the in-house nutrient database LEBTAB, which is based on the German standard food tables for common foods including mature human milk. LEBTAB also contains detailed data on ingredients, energy and nutrients generated by simulation of recipes of commercial foods and is continuously updated ${ }^{(19)}$.

\section{Antbropometric data}

Anthropometric measurements were performed within $14 \mathrm{~d}$ before or after the dietary record by trained nurses according to standardized procedures. Body weight was assessed unclothed using an electronic scale $( \pm 100 \mathrm{~g}$; Mettler PS 15; Mettler Toledo, Columbus, OH, USA). Daily weight gain during defined age intervals analogous to the reference data (in months), i.e. 0-3, 3-6, 6-9 and $9-12^{(12,20)}$, was calculated as the difference in weight between two consecutive measurements (birth weight in the case of the 3-month examination) divided by the number of days between the measurements.

\section{Statistical analysis}

Records from infants whose weight decreased between two consecutive measurements and implausible records, as determined by the ratio of reported EI to estimated $\mathrm{BMR}^{(21,22)}$, were excluded. This selection resulted in a sample of 323 children (165 boys, 158 girls), providing $7583 \mathrm{~d}$ dietary records ( 379 from boys, 379 from girls). In $89.8 \%$ of these records more than $90 \%$ of recorded food items were weighed, while $10 \cdot 2 \%$ of the records consisted of 50-90\% weighed food items. EI (total, breast milk, formula, other food) per day was calculated as the individual mean of the three recording days.

ER was calculated for boys and girls separately, at the time of measurement. Three different equations derived from $\mathrm{RER}^{(12)}$ were used:

1. Equation_1: adoption of the RER stated as ' $\mathrm{kJ} / \mathrm{d}$ ' (according to age and sex) ${ }^{(12)}$.

2. Equation_2: product of individual measured body weight and RER stated as ' $\mathrm{kJ} / \mathrm{kg}$ body weight per d' (according to age and sex) ${ }^{(12)}$.

3. Equation_3: sum of individual calculated total energy expenditure (TEE) and energy cost of growth (ECG) assuming published values ${ }^{(12,20)}$, where

$$
\text { TEE }(\mathrm{kJ} / \mathrm{d})=92.8 \times \text { weight }(\mathrm{kg})-152
$$


and

$$
\begin{aligned}
& \text { ECG }(\mathrm{kJ} / \mathrm{d}) \text { during a 3-month interval } \\
& =\text { individual weight gain }(\mathrm{g} / \mathrm{d}) \\
& \quad \times \text { energy cost of tissuedeposition }(\mathrm{kJ} / \mathrm{g}) .
\end{aligned}
$$

To evaluate growth characteristics, mean body weight was compared with the reference body weight ${ }^{(23)}$ taken from the 50th percentile of the WHO pooled breast-fed data set that was used for calculation of the $\mathrm{RER}^{(12)}$.

Infants in this sample were subdivided into four age categories defined as $3( \pm 0.5), 6( \pm 0.5), 9( \pm 0.5)$ and 12 $( \pm 0.5)$ months of age, in accordance with the reference data $^{(12,20)}$. To investigate the difference between the results from the three equations and $\mathrm{EI}$ in each of the four age groups, a paired $t$ test (PROC MEANS) was used. To graphically assess the agreement of the three equations with EI, Bland-Altman plots were used. The ratio of ER from each equation to EI was calculated for each subject, as were the mean and standard deviation for the total sam$\mathrm{ple}^{(24,25)}$. The Statistical Analysis System (SAS) statistical software package version 8.02 (SAS Institute, Cary, NC, USA) was used for data analysis. The level of significance was set at $P<0.05$.

\section{Ethical considerations}

The DONALD Study is purely observational and noninvasive and has been approved by the ethical committee of the Rheinische Friedrich-Wilhelms-University, Bonn, Germany. All examinations and assessments were performed with parental consent and later on with the children's consent.

\section{Results}

Growth characteristics of the DONALD sample were very close to the WHO reference population (Fig. 1, Table 1). EI adjusted for body weight $(\mathrm{kJ} / \mathrm{kg}$ per $\mathrm{d})$ in the DONALD sample decreased during the first half-year of life and tended to plateau afterwards, similar to the RER (Fig. 2) ${ }^{(12)}$.

The proportion of breast-fed infants decreased during the second six months of life from $86 \%$ at the age of 6 months to $17 \%$ at 12 months (Table 2). Accordingly, the proportions of breast milk, formula and complementary food contributing to total EI changed with increasing age (Fig. 3, Table 3). Overall EI (kJ/d) increased steadily from 3 to 12 months. EI from assumed fixed volumes of breast milk, as suggested in the literature ${ }^{(2,8)}$, was higher than the EI from measured breast milk consumption in our sample except for the 3-month-old infants ${ }^{(2,8)}$ (Fig. 3). The day-to-day variance of EI between the three recorded days ranged from $8 \%$ to $11 \%$ of the group's mean EI (Table 3).

Equation_1 and Equation_2 for ER underestimated EI for all age groups and both genders (Fig. 4, Table 4). Equation_1 showed significant deviations from the mean EI in boys at all age groups and in girls at 9 and 12 months. Equation_2 showed smaller but significant deviations from EI than Equation_1. In contrast, Equation_3 overestimated EI for 3-month-old and 3- and 6month-old girls and underestimated EI for older infants similar to Equation_2. Overall, the best agreement between ER and EI was found at the age of 6 months and the largest differences were found at 9 and 12 months.

Bland-Altman plots of the ratio between EI and ER $v$. the average of EI and ER gave similar results for the three

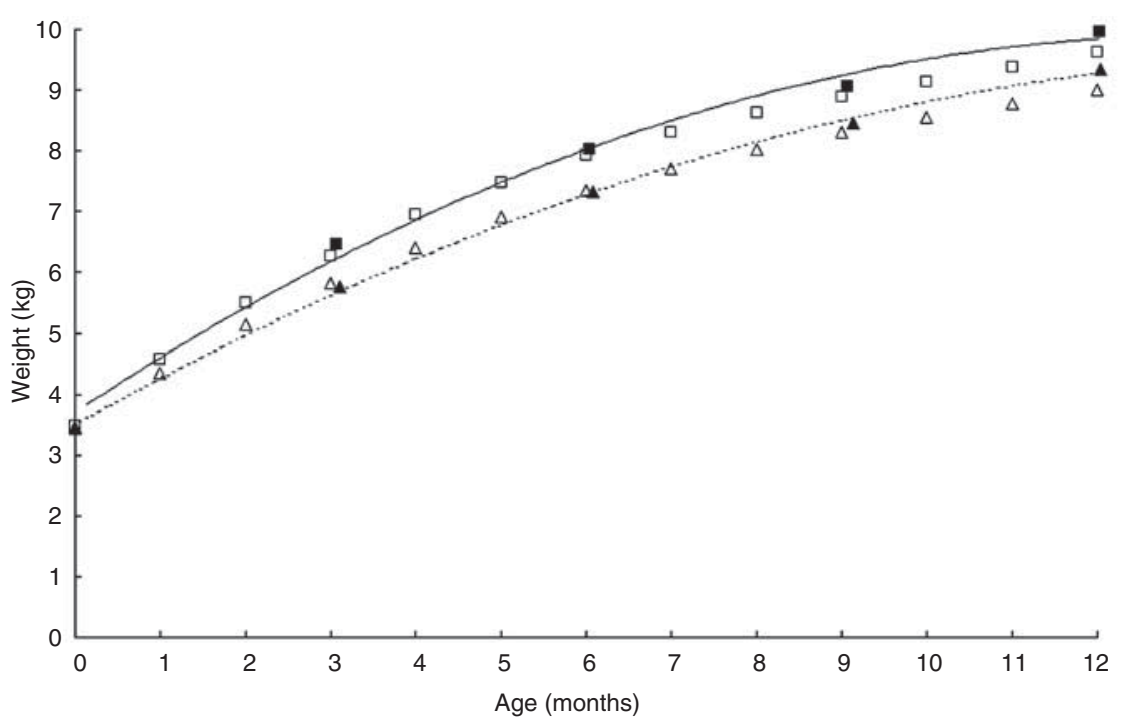

Fig. 1 Mean values of body weight of infants ( $\mathbf{\square}$, boys; $\boldsymbol{\Lambda}$, girls) from the DONALD (DOrtmund Nutritional and Anthropometric Longitudinally Designed) Study sample at 0, 3, 6, 9 and 12 months of age, together with gender-specific trend lines (-, boys; ---, girls), compared with reference body weight of infants ( $\square$, boys; $\triangle$, girls) aged 0-12 months from the 50th percentile of the WHO pooled breast-fed data set ${ }^{(23)}$. Trend line in DONALD boys: weight $=-0.0346 \times a^{2}+0.9269 \times$ age $+3 \cdot 7073$; trend line in DONALD girls: weight $=-0.0247 \times$ age $^{2}+0.7779 \times$ age +3.504 
Table 1 Weight gain $(\mathrm{g} / \mathrm{d})$ from the reference data (50th percentile of the WHO pooled breast-fed data set ${ }^{(23)}$ ) and in the DONALD (DOrtmund Nutritional and Anthropometric Longitudinally Designed) Study sample by gender and age

\begin{tabular}{lccc}
\hline & & \multicolumn{2}{c}{ DONALD weight gain $(\mathrm{g} / \mathrm{d})$} \\
\cline { 3 - 4 } Age interval (months) & WHO weight gain $(\mathrm{g} / \mathrm{d})$ & Mean & SD \\
\hline Boys & & & 8 \\
$0-3$ & 30 & 32 & 5 \\
$3-6$ & 17 & 20 & 5 \\
$6-9$ & 11 & 12 & 4 \\
$9-12$ & 8 & 26 & 5 \\
Girls & 28 & 18 & 5 \\
$0-3$ & 16 & 12 & 4 \\
$3-6$ & 10 & 10 & 4 \\
$6-9$ & 6 & & \\
$9-12$ & & & \\
\hline
\end{tabular}

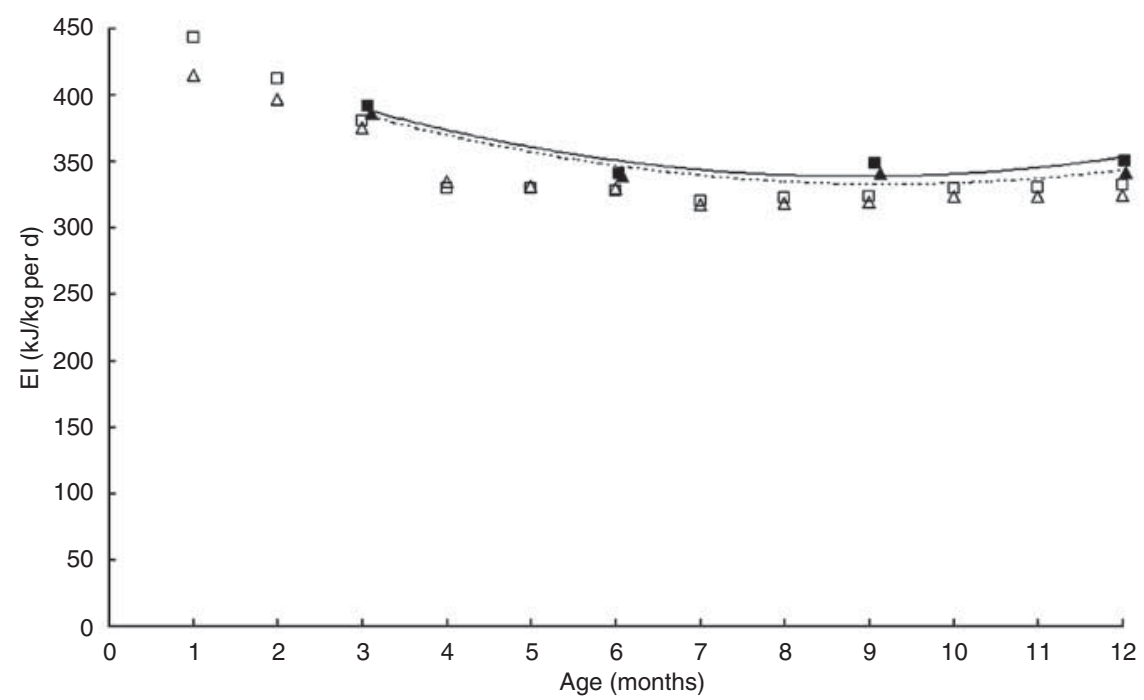

Fig. 2 Energy intake (EI) from measured food consumption adjusted for body weight of infants ( $\mathbf{\square}$, boys; $\boldsymbol{\Delta}$, girls) from the DONALD (DOrtmund Nutritional and Anthropometric Longitudinally Designed) Study sample at 3, 6, 9 and 12 months of age, together with gender-specific trend lines (-, boys; - - , girls), compared with reference energy requirements for boys $(\square)$ and $(\triangle)$ girls $^{(12)}$. Trend line in DONALD boys: weight $=1 \cdot 482 \times$ age $^{2}-26 \cdot 266 \times$ age $+454 \cdot 5$; trend line in DONALD girls: weight $=1 \cdot 3687$ $\times$ age $^{2}-25 \cdot 226 \times$ age $+448 \cdot 66$

Table 2 Dietary characteristics of infants from the DONALD (DOrtmund Nutritional and Anthropometric Longitudinally Designed) Study

\begin{tabular}{|c|c|c|c|c|c|c|c|c|c|c|c|c|}
\hline \multirow{2}{*}{$\begin{array}{l}\text { Age } \\
\text { (months) }\end{array}$} & \multicolumn{2}{|c|}{$\begin{array}{l}\text { Breast milk } \\
\quad \text { only }\end{array}$} & \multicolumn{2}{|c|}{$\begin{array}{c}\text { Breast } \\
\text { milk + formula }\end{array}$} & \multicolumn{2}{|c|}{$\begin{array}{l}\text { Breast milk }+ \\
\text { complementary food }\end{array}$} & \multicolumn{2}{|c|}{$\begin{array}{l}\text { Breast milk }+ \text { formula }+ \\
\text { complementary food }\end{array}$} & \multicolumn{2}{|c|}{$\begin{array}{l}\text { Formula }+ \text { complementary } \\
\text { food }\end{array}$} & \multicolumn{2}{|c|}{$\begin{array}{l}\text { Complementary } \\
\text { food only }\end{array}$} \\
\hline & $n$ & $\%$ & $n$ & $\%$ & $n$ & $\%$ & $n$ & $\%$ & $n$ & $\%$ & $n$ & $\%$ \\
\hline 3 & 125 & 100 & 0 & & 0 & & 0 & & 0 & & 0 & \\
\hline 6 & 37 & 19 & 2 & 1 & 102 & 53 & 26 & 13 & 23 & 12 & 3 & 2 \\
\hline 9 & 0 & & 0 & & 62 & 29 & 29 & 14 & 92 & 43 & 30 & 14 \\
\hline 12 & 0 & & 0 & & 30 & 13 & 10 & 4 & 91 & 40 & 96 & 42 \\
\hline
\end{tabular}

equations and therefore only the results for Equation_3 are shown (Fig. 5). The mean ratio was 1.03 and the $95 \%$ limits of agreement were $0 \cdot 69,1 \cdot 37$. Thus, EI was underestimated by up to $31 \%$ and overestimated by up to $37 \%$ for most measurements. The gender-specific regression lines show a small but significant increase in the ratio as the average increases (boys: EI:ER calculated by Equation_3 $=0 \cdot 80582+0 \cdot 000075 \times$ mean, $R^{2}=0 \cdot 04$,
$P=0 \cdot 0002$; girls: EI:ER calculated by Equation_3 $=$ $0 \cdot 906516+0 \cdot 000043 \times$ mean, $\left.R^{2}=0 \cdot 01, P=0 \cdot 0223\right)$.

\section{Discussion}

The objective of the present study was to facilitate the estimation of breast milk consumption in epidemiological 


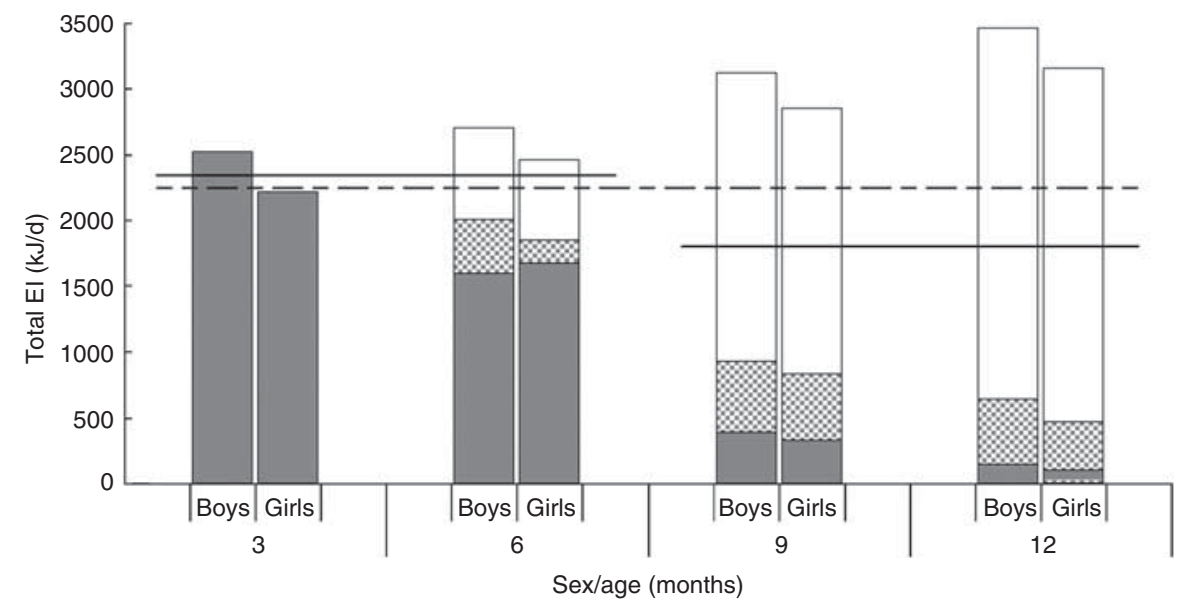

Fig. 3 Total energy intake (EI) assessed by $3 \mathrm{~d}$ weighed dietary records differentiated for breast milk ( $\square$ ), formula (国) and complementary food ( $\square$ ) from the DONALD (DOrtmund Nutritional and Anthropometric Longitudinally Designed) Study sample at $3,6,9$ and 12 months of age, compared with energy from an assumed amount of breast milk (-, $780 \mathrm{ml}(3$ and $6 \mathrm{months})$ or $600 \mathrm{ml}$ $\left(9\right.$ and 12 months) $\left.{ }^{(2,8)} ;---, 750 \mathrm{ml}^{(2,8)}\right)$

Table 3 Total energy intake, energy intake from breast milk, formula and complementary food, and mean day-to-day variance by gender and age in the DONALD (DOrtmund Nutritional and Anthropometric Longitudinally Designed) Study sample

\begin{tabular}{|c|c|c|c|c|c|c|c|c|c|}
\hline \multirow{2}{*}{$\begin{array}{l}\text { Age category } \\
\text { (months) }\end{array}$} & \multicolumn{2}{|c|}{$\begin{array}{l}\text { Total energy intake } \\
(\mathrm{kJ} / \mathrm{d})\end{array}$} & \multicolumn{2}{|c|}{$\begin{array}{l}\text { Energy intake from } \\
\text { breast milk }(\mathrm{kJ} / \mathrm{d})\end{array}$} & \multicolumn{2}{|c|}{$\begin{array}{l}\text { Energy intake from } \\
\text { formula }(\mathrm{kJ} / \mathrm{d})\end{array}$} & \multicolumn{2}{|c|}{$\begin{array}{c}\text { Energy intake from } \\
\text { complementary food }(\mathrm{kJ} / \mathrm{d})\end{array}$} & \multirow{2}{*}{$\begin{array}{l}\text { Mean day-to-day variance } \\
\text { (\% of total energy intake) }\end{array}$} \\
\hline & Mean & SD & Mean & SD & Mean & SD & Mean & SD & \\
\hline \multicolumn{10}{|l|}{ Boys } \\
\hline 3 & 2524 & 434 & 2524 & 434 & 0 & 0 & 0 & 0 & $8 \cdot 5$ \\
\hline 6 & 2707 & 376 & 1597 & 1081 & 415 & 739 & 696 & 751 & $9 \cdot 6$ \\
\hline 9 & 3124 & 472 & 396 & 604 & 541 & 599 & 2187 & 748 & $8 \cdot 4$ \\
\hline 12 & 3462 & 471 & 151 & 468 & 492 & 675 & 2819 & 835 & $10 \cdot 0$ \\
\hline \multicolumn{10}{|l|}{ Girls } \\
\hline 3 & 2216 & 318 & 2215 & 318 & 0 & 0 & 1 & 5 & $8 \cdot 7$ \\
\hline 6 & 2461 & 330 & 1680 & 848 & 171 & 443 & 610 & 675 & $8 \cdot 6$ \\
\hline 9 & 2853 & 421 & 332 & 559 & 502 & 551 & 2019 & 734 & $8 \cdot 1$ \\
\hline 12 & 3163 & 418 & 101 & 322 & 373 & 522 & 2690 & 640 & $10 \cdot 6$ \\
\hline
\end{tabular}

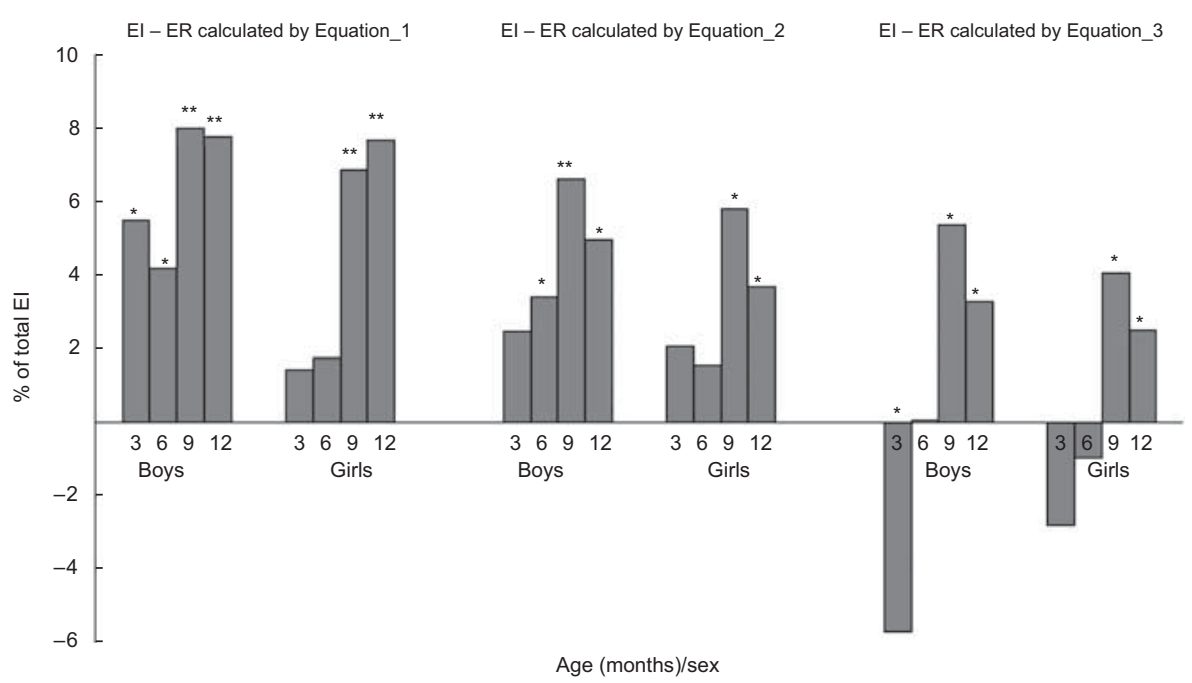

Fig. 4 Difference between total measured energy intake (EI) and energy requirements (ER) estimated using three equations (Equation_1, Equation_2, Equation_3), displayed as a percentage of El, in the DONALD (DOrtmund Nutritional and Anthropometric Longitudinally Designed) Study sample at 3, 6, 9 and 12 months of age. ${ }^{\star} P<0.05,{ }^{\star \star} P<0.0001$ 
Table 4 Difference between energy intake $(E I)$ and energy requirements $(E R)$, calculated using the three different equations, by gender and age in the DONALD (DOrtmund Nutritional and Anthropometric Longitudinally Designed) Study

\begin{tabular}{|c|c|c|c|c|c|c|c|}
\hline \multirow{2}{*}{$\begin{array}{l}\text { Age category } \\
\text { reference (months) }\end{array}$} & \multirow[b]{2}{*}{$n$} & \multicolumn{2}{|c|}{$\begin{array}{l}\text { EI - ER calculated by } \\
\text { Equation_1 (kJ) }\end{array}$} & \multicolumn{2}{|c|}{$\begin{array}{c}\text { EI - ER calculated by } \\
\text { Equation_2 }(\mathrm{kJ})\end{array}$} & \multicolumn{2}{|c|}{$\begin{array}{c}\text { EI - ER calculated by } \\
\text { Equation_3 (kJ) }\end{array}$} \\
\hline & & Mean & $P$ & Mean & $P$ & Mean & $P$ \\
\hline \multicolumn{8}{|l|}{ Boys } \\
\hline 3 & 60 & $138 \cdot 7$ & 0.0162 & $62 \cdot 1$ & 0.2262 & $-144 \cdot 7$ & 0.0193 \\
\hline 6 & 96 & $113 \cdot 2$ & 0.0044 & $91 \cdot 9$ & 0.0233 & $1 \cdot 4$ & 0.9745 \\
\hline 9 & 117 & $249 \cdot 6$ & $<0.0001$ & $206 \cdot 8$ & $<0.0001$ & $167 \cdot 9$ & 0.0020 \\
\hline 12 & 115 & $269 \cdot 7$ & $<0.0001$ & $171 \cdot 7$ & 0.0004 & $113 \cdot 4$ & 0.0241 \\
\hline \multicolumn{8}{|l|}{ Girls } \\
\hline 3 & 65 & $31 \cdot 8$ & 0.4237 & $45 \cdot 7$ & 0.2235 & $-62 \cdot 0$ & 0.1217 \\
\hline 6 & 100 & $42 \cdot 7$ & $0 \cdot 2007$ & $38 \cdot 1$ & 0.2946 & $-24 \cdot 0$ & 0.5728 \\
\hline 9 & 101 & $196 \cdot 2$ & $<0.0001$ & $166 \cdot 2$ & 0.0002 & $116 \cdot 0$ & 0.0141 \\
\hline 12 & 119 & $242 \cdot 8$ & $<0.0001$ & $117 \cdot 0$ & 0.0055 & $79 \cdot 0$ & 0.0753 \\
\hline
\end{tabular}

Equation_1: adoption of the published reference ER (RER) stated as ' $\mathrm{kJ} / \mathrm{d}$ '.

Equation_2: product of the individual measured body weight and RER stated as ' $\mathrm{kJ} / \mathrm{kg}$ body weight per d'.

Equation_3: sum of individual estimated total energy expenditure (TEE) and energy cost of growth (ECG).

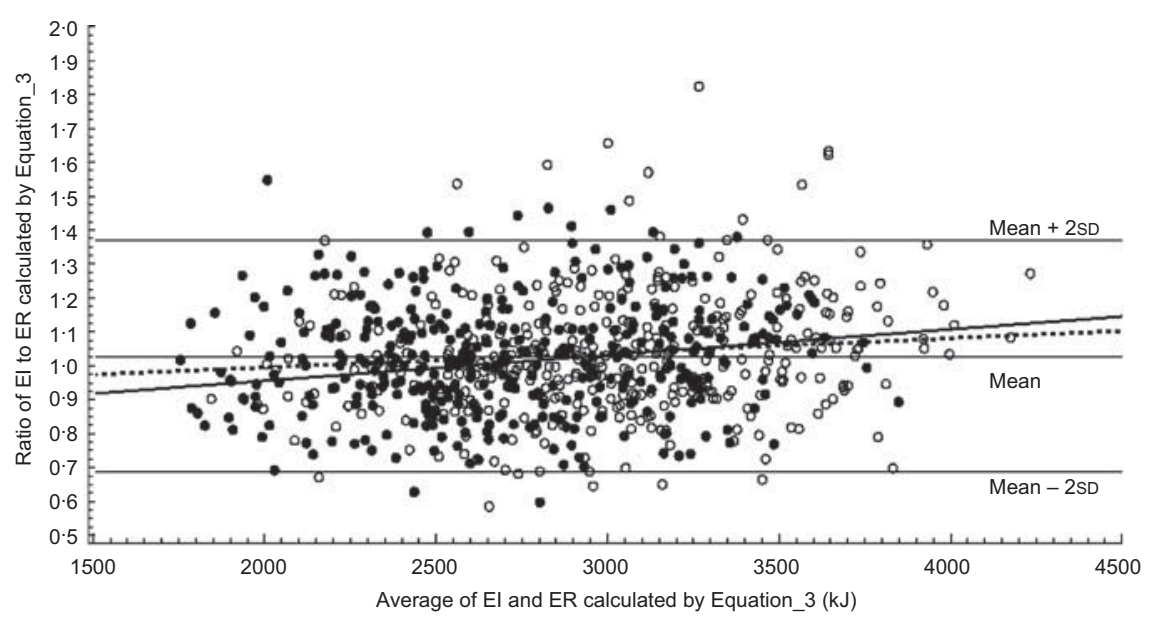

Fig. 5 Bland-Altman plot of the ratio between energy intake (EI) and energy requirements (ER) calculated by Equation_3 $v$. the average of EI and ER calculated by Equation_3 for infants ( $\bigcirc$, boys; $\bullet$, girls) of the DONALD (DOrtmund Nutritional and Anthropometric Longitudinally Designed) Study sample at 3, 6, 9 and 12 months of age and the gender-specific regression lines (-, boys; - - - girls)

studies among healthy infants where measurement of breast milk intake is not possible. Nutrition in early infancy is increasingly considered to be an important factor influencing later health. However, public health strategies to examine the effects of breast-feeding promotion on breast-feeding habits remain to be conducted. Validated equations to estimate breast milk consumption requiring only body weight measurements would be of great interest.

We based our evaluation on EI measured by $3 \mathrm{~d}$ weighed dietary records, which are considered to be the gold standard among nutrition survey methods. Moreover, our sample fulfilled the same starting criteria as those used for the sample from which the RER were derived, and growth was very similar to the WHO references used to construct the $\operatorname{RER}^{(12)}$. We cannot demonstrate whether our assumption of self-regulation of EI by ER was true for our sample, but nevertheless we could draw on published data from infants aged up to 12 months $^{(6,10)}$. Self-regulation seems to be less complete in infants or toddlers, when environmental influences such as feeding habits of carers gain more importance ${ }^{(10,26,27)}$.

The main result of our study was that using an infant's body weight alone (Equation_2) or the infant's body weight together with weight gain (Equation_3) is a reasonable approach for estimating EI throughout the first year of life in infants breast-fed for at least 4 months.

Equation_2 is the more practical of the two equations because only the actual weight of the infant is required. On the other hand, taking weight gain into account (Equation_3) could improve the estimation of ER in the case of infants with fast or slow weight gain.

Equation_1, with the highest differences between ER and EI, is based upon the simple adoption of the RER, stated as ' $\mathrm{kJ} / \mathrm{d}$ ', which takes into account age and sex but not weight. Weight is a crucial predictor of $\mathrm{EI}^{(12,18)}$. Since the DONALD 
Study sample was marginally heavier than the WHO reference population, a higher EI was to be expected.

The overall differences between EI and ER were rather small, never more than $10 \%$ of total energy intake, and smaller than the mean variance of energy intake between the three days of recording. The difference was also much smaller than the standard deviation of the mean TEE in the reference population, which was always higher than $10 \%$. Regarding the individual ratios of EI:ER (BlandAltman plots), the findings strongly advise caution in applying our approach at an individual level. However, the fact that the mean ratio approached one suggests that our approach is reliable for groups of healthy, normally growing infants during the first year of life.

All three equations for ER underestimated EI for nearly all age groups and both genders. Several explanations are possible. First, correcting breast milk intake by adding 5\% for insensible water loss might have led to an overestimation of total EI. The influence of this correction should be larger at younger ages because of a higher percentage of breast milk contributing to the overall intake, but in our sample differences were larger in the older age groups. Second, the discrepancy between the metabolisable energy content and the gross energy content of breast milk was not considered in the RER. If we had used the suggested value for the metabolisable energy content $(259 \mathrm{~kJ} / 100 \mathrm{~g})^{(28)}$ instead of the one for gross energy content $(289 \mathrm{~kJ} / 100 \mathrm{~g})$, our measured EI would have been lower by approximately $10 \%$, at least for the predominantly breast-fed infants. At present there is no agreement as to whether metabolisable or gross EI of human milk is more appropriate ${ }^{(29)}$. Third, the weight gain of the DONALD sample was marginally higher than that of the WHO reference sample for nearly all age groups conditioned by a higher EI, which might have led to a higher body weight at the age of 12 months. Fourth, information on the dietary intake of the reference population is available only for the first four months, so we cannot check for potential differences in dietary characteristics between the reference population ${ }^{(12)}$ and our sample after this age. Finally, our sample reflects dietary habits in countries where breast-feeding rates at 6 months are much lower than recommended and negligible at the age of 9 and 12 months. It would probably have been more appropriate to use non-breast-fed infants, whose RER are higher than for breast-fed infants, as a reference in the second six months. However, this would imply that the reference needs to be switched during the first year of life although no information on diet is available for the reference infants after the first four months. Future studies could investigate our approach for formula-fed infants or for infants without regard to their type of milk feeding.

Only Equation_3, which took weight gain into account, resulted in an overestimation of EI for the youngest age groups of 3 and 6 months. This is probably a methodological artefact. During this age period the earlier peak growth rate decreased rapidly, whereas the mean daily individual weight gain during the preceding age interval (for instance, $0-3$ months) was used to calculate Equation_3 (at month 3). In reality, the individual growth rate would already be lower at this time point ${ }^{(30)}$. Depending on whether a child is in a period of fast growth or not, the energy cost of growth could be unpredictable at the time of measurement.

In general, the significant but clinically not relevant differences between ER and EI in our evaluation suggest that the current, well-documented RER data ${ }^{(12)}$ can be applied to calculate ER in breast-fed infants whose growth trajectory follows the WHO growth curves. This approach seems to be more valid than the simple assumption of a constant volume of breast milk for a wide age range ${ }^{(2,8)}$. Our results show that Equation_3 can be used if body weight and weight gain are available and Equation_2 if body weight is measured only once. Equation_1 gives only a rough impression of the RER and should only be used if body measurements are not available.

The dietary guidelines for infant nutrition in Germany are in agreement with the latest statement from the European Society for Paediatric Gastroenterology, Hepatology and Nutrition's (ESPGHAN) Committee on Nutrition, valid for the European region. Thus, the infant feeding style in Germany should be similar to that in other European countries ${ }^{(31)}$. Therefore, our findings, based on a German study sample, should be applicable to other groups of infants fed according to the European recommendations.

In conclusion, our study, using weighed dietary records in infants from the DONALD Study, has shown that breast milk amounts in predominantly or partially breast-fed infants can be estimated with reasonable precision from calculated ER based on the current RER data $^{(12)}$. Put into practice, this means: (i) exclusively breast-fed infants consume as much energy via breast milk as given by their calculated ER; and (ii) partially breast-fed infants consume as much energy via breast milk as given by the difference between their ER and the EI of foods other than breast milk. Nevertheless, a possible bias due to the lack of self-regulation should always be considered if our method is applied. Various standard methods such as dietary records or recalls are available to quantify the consumption of other food by infants, e.g. formula, complementary menus and cereals. Together with our proposed method for estimating breast milk consumption, assessing dietary intake in epidemiological studies in infants should be easier in the future and may also support the monitoring of breast milk promotion.

\section{Acknowledgements}

The DONALD Study is supported by the Ministry of Innovation, Science, Research and Technology of NordrheinWestfalen, Germany. None of the authors had any conflict 
of interest. S.S. analysed the data, drafted and edited the manuscript. W.S.-H. and M.K. contributed significantly to the discussion and to the critical revision of the manuscript. We are grateful to Shoma Berkemeyer for inputs on the manuscript and to Nadina Karaolis-Danckert for proofreading.

\section{References}

1. Haisma H, Coward WA, Albernaz E, Visser GH, Wells JC, Wright A \& Victora CG (2003) Breast milk and energy intake in exclusively, predominantly, and partially breast-fed infants. Eur J Clin Nutr 57, 1633-1642.

2. Skinner JD, Carruth BR, Houck KS, Coletta F, Cotter R, Ott D \& McLeod M (1997) Longitudinal study of nutrient and food intakes of infants aged 2 to 24 months. J Am Diet Assoc 97, 496-504.

3. Butte NF, Garza C, Smith EO \& Nichols BL (1984) Human milk intake and growth in exclusively breast-fed infants. J Pediatr 104, 187-195.

4. Dewey KG, Heinig MJ, Nommsen LA \& Lonnerdal B (1991) Adequacy of energy intake among breast-fed infants in the DARLING study: relationships to growth velocity, morbidity, and activity levels. Davis Area Research on Lactation, Infant Nutrition and Growth. J Pediatr 119, 538-547.

5. Emmett P, North K \& Noble S (2000) Types of drinks consumed by infants at 4 and 8 months of age: a descriptive study. The ALSPAC Study Team. Public Health Nutr 3, 211-217.

6. Dewey KG \& Lonnerdal B (1986) Infant self-regulation of breast milk intake. Acta Paediatr Scand 75, 893-898.

7. Ong KK, Emmett PM, Noble S, Ness A \& Dunger DB (2006) Dietary energy intake at the age of 4 months predicts postnatal weight gain and childhood body mass index. Pediatrics 117, e503-e 508.

8. Devaney B, Kalb L, Briefel R, Zavitsky-Novak T, Clusen N \& Ziegler P (2004) Feeding infants and toddlers study: overview of the study design. J Am Diet Assoc 104, Suppl. $1, \mathrm{~S} 8-\mathrm{S} 13$.

9. Scanlon KS, Alexander MP, Serdula MK, Davis MK \& Bowman BA (2002) Assessment of infant feeding: the validity of measuring milk intake. Nutr Rev 60, 235-251.

10. Fox MK, Devaney B, Reidy K, Razafindrakoto C \& Ziegler P (2006) Relationship between portion size and energy intake among infants and toddlers: evidence of selfregulation. J Am Diet Assoc 106, Suppl. 1, S77-S83.

11. Food and Agriculture Organization of the United Nations (2004) Human Energy Requirements. Report of a Joint FAO/WHO/UNU Expert Consultation, Rome, 17-24 October 2001. Food and Nutrition Technical Report Series no. 1. Rome: FAO.

12. Butte NF (2005) Energy requirements of infants. Public Health Nutr 8, 953-967.

13. Kersting M, Alexy U, Sichert-Hellert W, Manz F \& Schoch G (1998) Measured consumption of commercial infant food products in German infants: results from the DONALD study. Dortmund Nutritional and Anthropometrical
Longitudinally Designed. J Pediatr Gastroenterol Nutr 27, 547-552.

14. Kroke A, Manz F, Kersting M, Remer T, Sichert-Hellert W, Alexy U \& Lentze MJ (2004) The DONALD Study. History, current status and future perspectives. Eur J Nutr 43, 45-54.

15. Kromeyer-Hauschild K, Wabitsch M, Kunze D, Geller F, Geiß H \& Hesse V (2001) Perzentile für den Body-massIndex für das Kindes-und Jugendalter unter Heranziehung verschiedener deutscher Stichproben. Monatsschr Kinderh 149, 807-818.

16. Kersting M \& Dulon M (2002) Assessment of breast-feeding promotion in hospitals and follow-up survey of motherinfant pairs in Germany: the SuSe Study. Public Health Nutr 5, 547-552.

17. World Health Organization (1991) Indicators for Assessing Breastfeeding Practices. Report of an Informal Meeting, 11-12 June 1991. WHO/CDD/SER/9114. Geneva: WHO.

18. Butte NF (1996) Energy requirements of infants. Eur J Clin Nutr 50, Suppl. 1, S24-S36.

19. Sichert-Hellert W, Kersting M, Chahda C, Schäfer R \& Kroke A (2007) German food composition database for dietary evaluations in children and adolescents. J Food Compost Anal 20, 63-70.

20. Butte NF, Hopkinson JM, Wong WW, Smith EO \& Ellis KJ (2000) Body composition during the first 2 years of life: an updated reference. Pediatr Res $\mathbf{4 7}, 578-585$.

21. Schofield WN (1985) Predicting basal metabolic rate, new standards and review of previous work. Hum Nutr Clin Nutr 39, Suppl. 1, 5-41.

22. Goldberg GR, Black AE, Jebb SA, Cole TJ, Murgatroyd PR, Coward WA \& Prentice AM (1991) Critical evaluation of energy intake data using fundamental principles of energy physiology: 1 . Derivation of cut-off limits to identify underrecording. Eur J Clin Nutr 45, 569-581.

23. World Health Organization (1994) An Evaluation of Infant Growth. Geneva: WHO.

24. Bland JM \& Altman DG (1999) Measuring agreement in method comparison studies. Stat Methods Med Res 8, $135-160$.

25. Bland JM \& Altman DG (1986) Statistical methods for assessing agreement between two methods of clinical measurement. Lancet 1, 307-310.

26. Mrdjenovic G \& Levitsky DA (2005) Children eat what they are served: the imprecise regulation of energy intake. Appetite 44, 273-282.

27. Farrow C \& Blissett J (2006) Does maternal control during feeding moderate early infant weight gain? Pediatrics 118, e293-e298.

28. Reilly JJ \& Wells JC (2005) Duration of exclusive breastfeeding: introduction of complementary feeding may be necessary before 6 months of age. Br J Nutr 94, 869-872.

29. Reilly JJ, Ashworth S \& Wells JC (2005) Metabolisable energy consumption in the exclusively breast-fed infant aged 3-6 months from the developed world: a systematic review. Br J Nutr 94, 56-63.

30. de Onis M \& Onyango AW (2003) The Centers for Disease Control and Prevention 2000 growth charts and the growth of breastfed infants. Acta Paediatr 92, 413-419.

31. Agostoni C, Decsi T, Fewtrell M et al. (2008) Complementary feeding: a commentary by the ESPGHAN Committee on Nutrition. J Pediatr Gastroenterol Nutr 46, 99-110. 